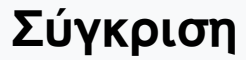

Tóp. 4 (1992)

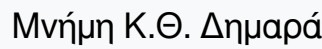

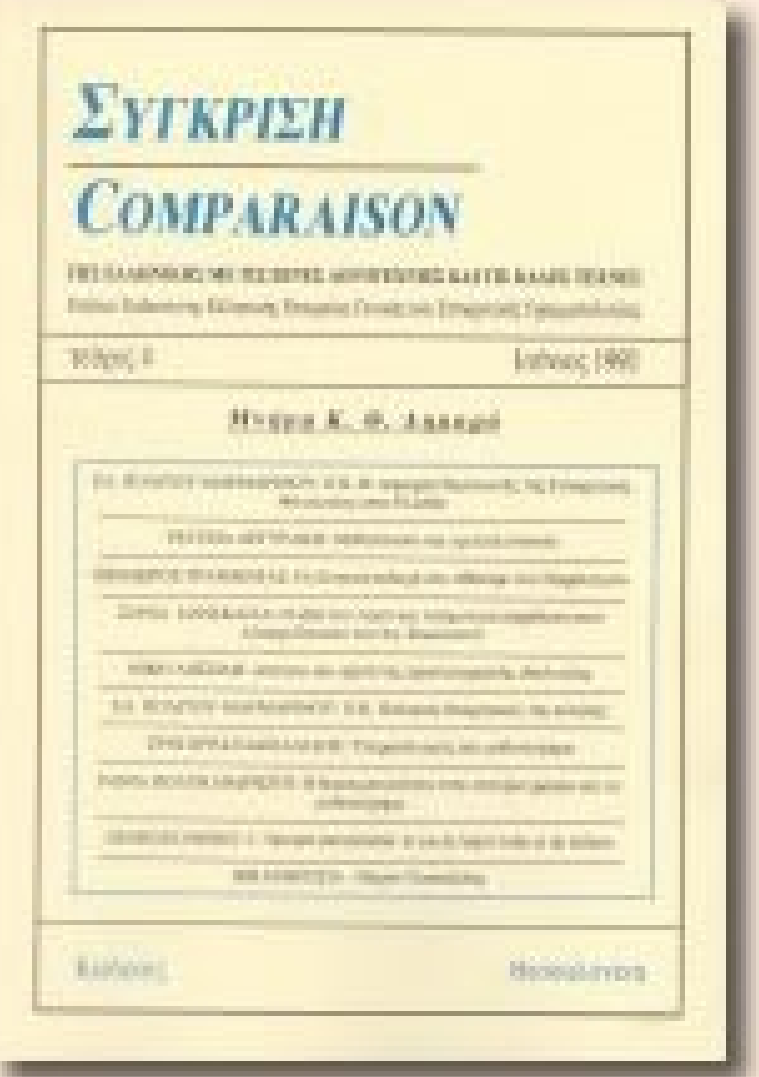

Armando Gnisci NOIALTRI EUROPEI, Bulzoni, 1991

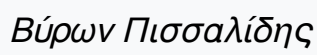

doi: $10.12681 /$ comparison.66

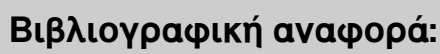

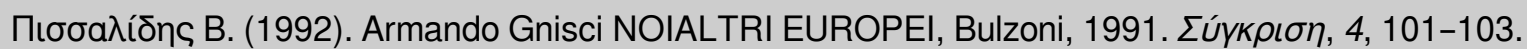
https://doi.org/10.12681/comparison.66 


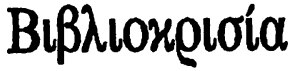

\section{Armando Gnisci \\ NOIALTRI EUROPEI, Bulzoni, 1991}

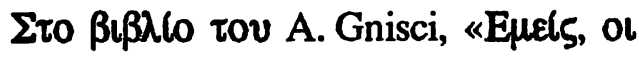

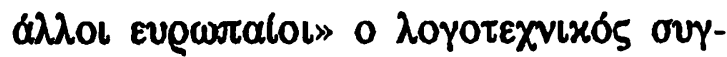

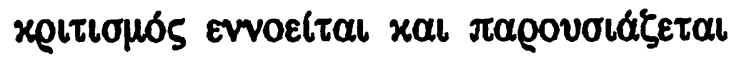

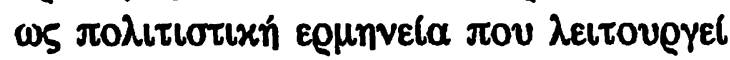

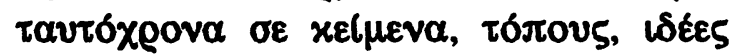

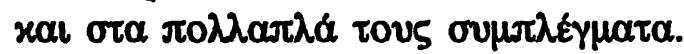

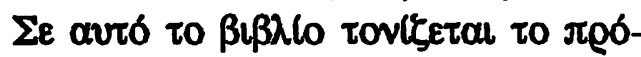

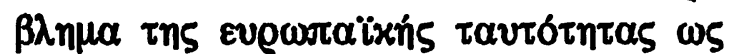

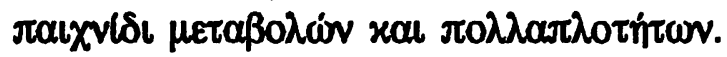

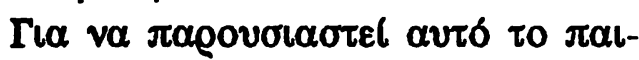

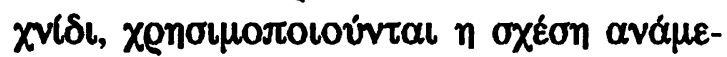

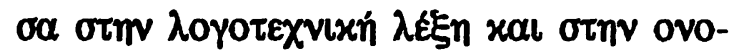

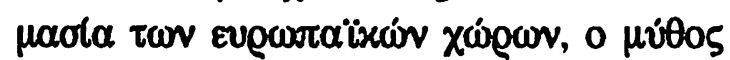

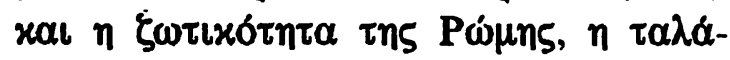

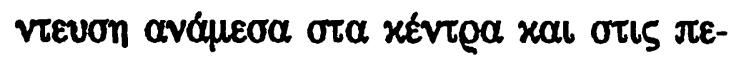

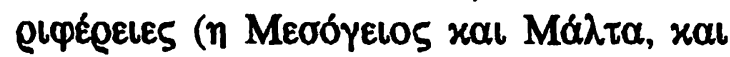

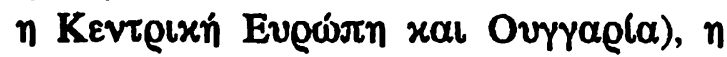

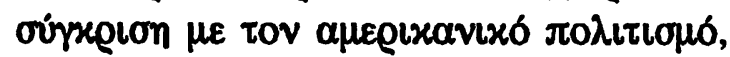

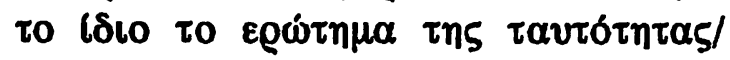

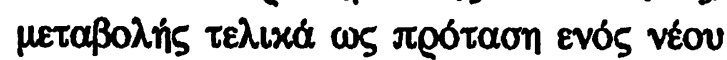

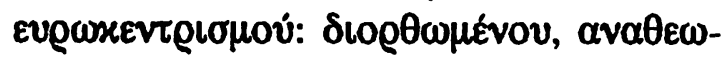

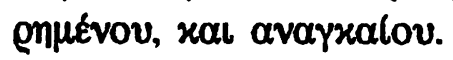

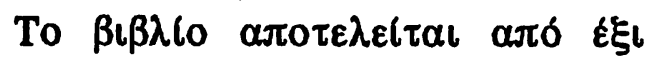

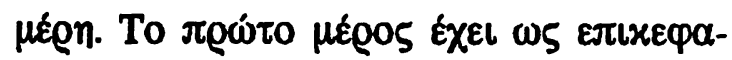

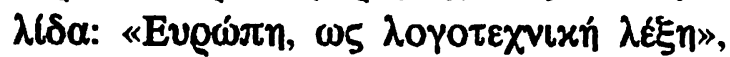

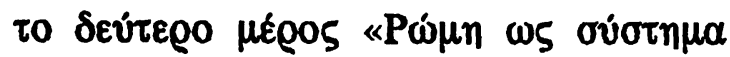

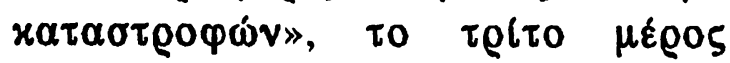

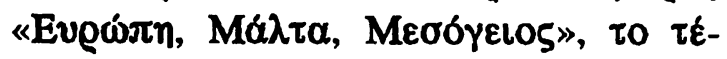

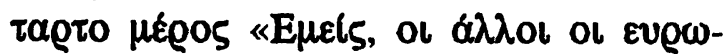

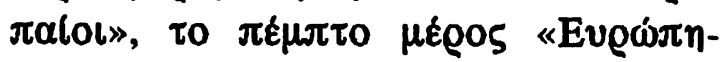

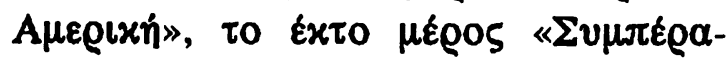
ora».

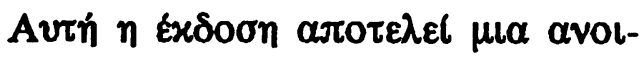

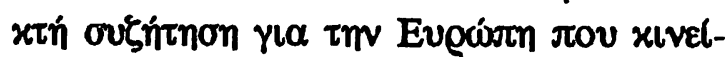

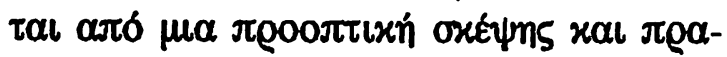

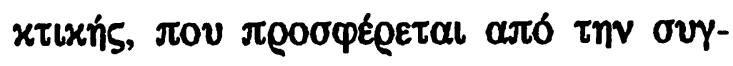

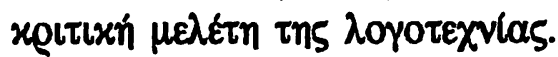

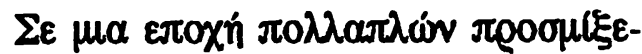

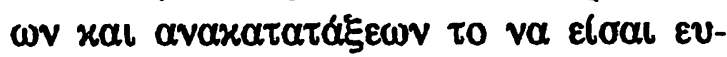

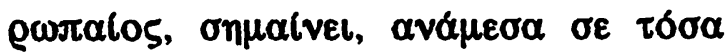

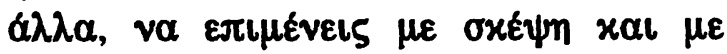

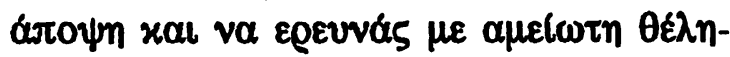

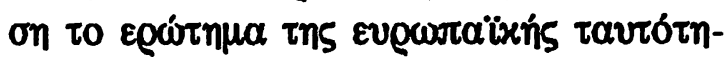
tas.

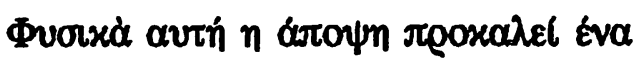

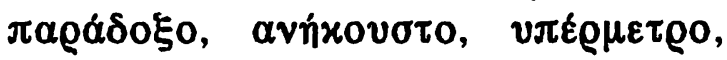

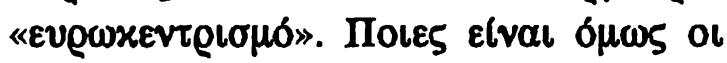

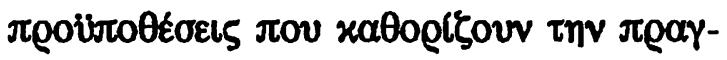

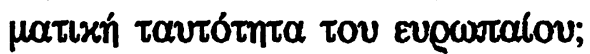

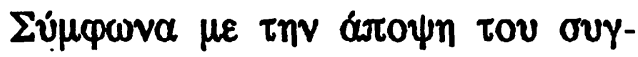

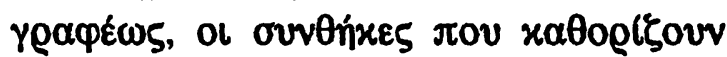

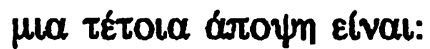

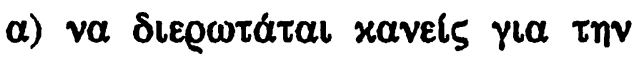

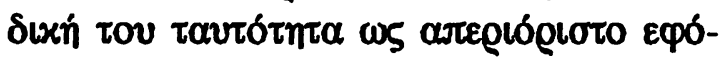

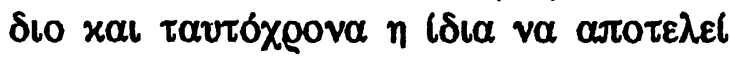

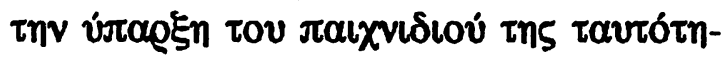
$\tau \alpha$,

B) to $v \alpha$ eival $x \alpha l$ va $\alpha v \alpha \gamma v \omega \rho i \zeta \varepsilon-$

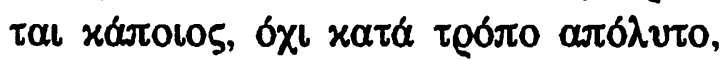

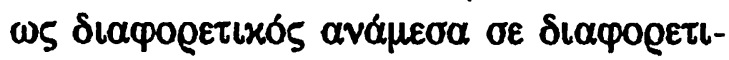

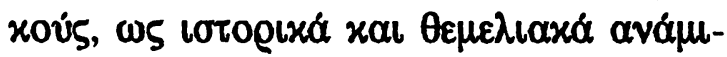

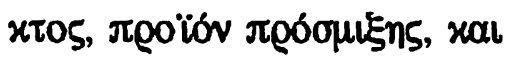

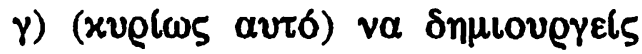

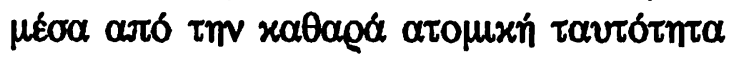

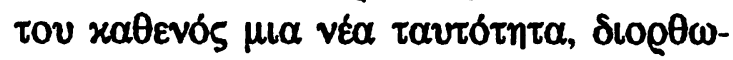

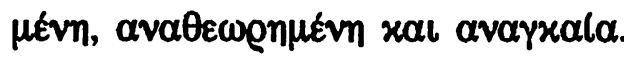

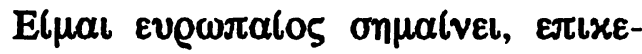

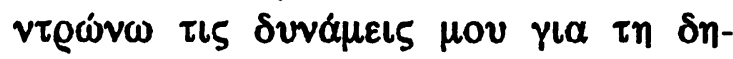

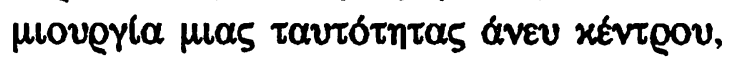

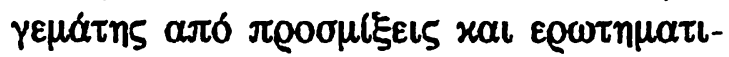




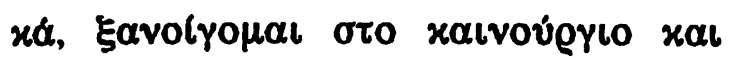

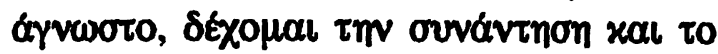

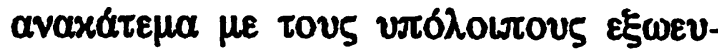
gwialous.

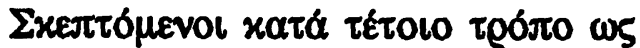

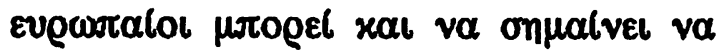

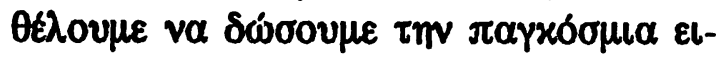

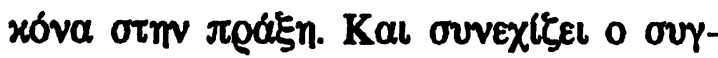

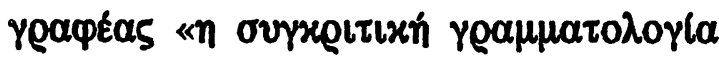

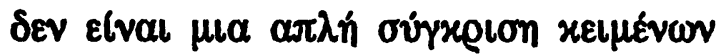

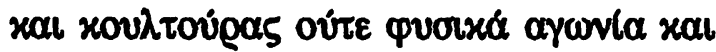

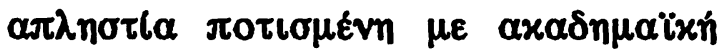

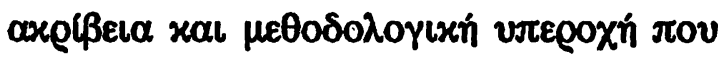

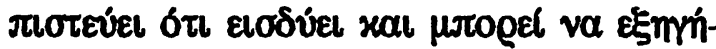

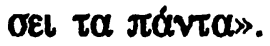

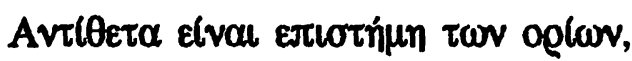

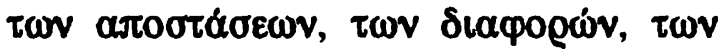

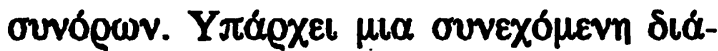

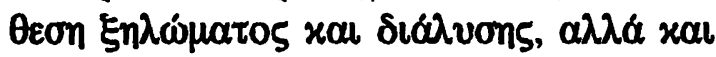

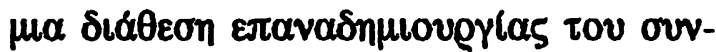

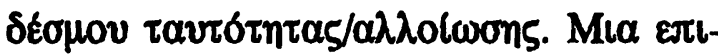

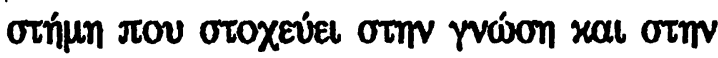

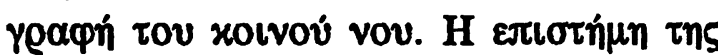

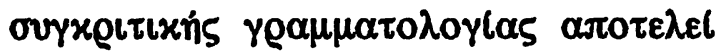

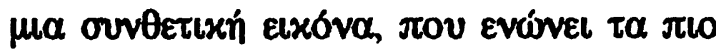

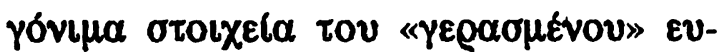

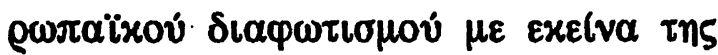

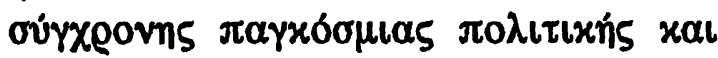
rovitovipas.

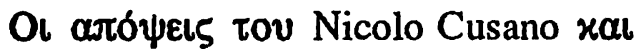

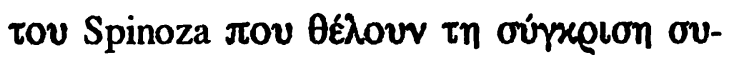

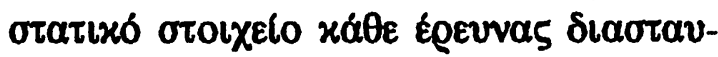

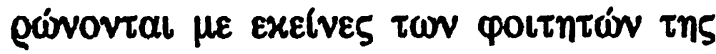

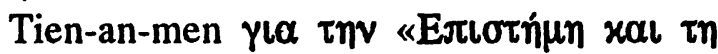
$\Delta$ nuoxgatla» xal ouvavtoúv tovs ớy-

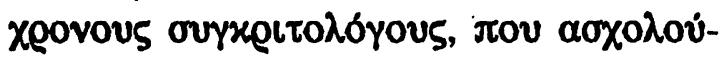

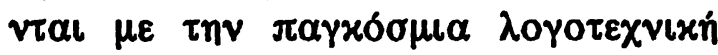

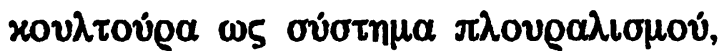

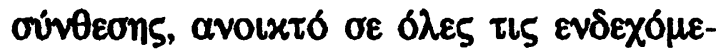

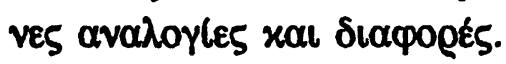

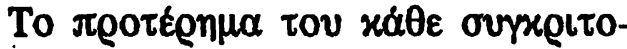

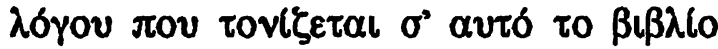

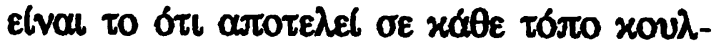

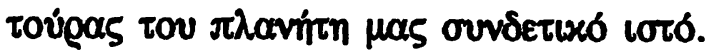

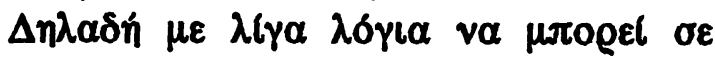

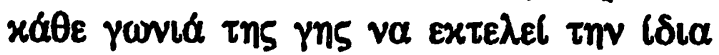

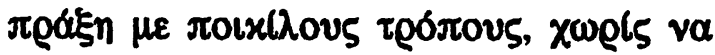

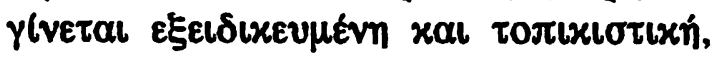

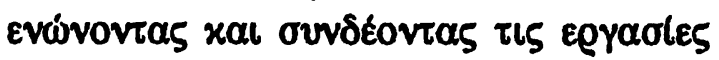

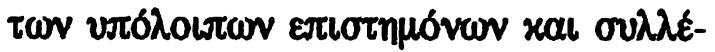

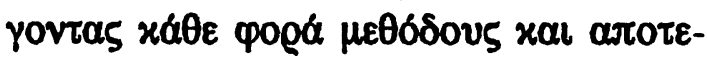
$\lambda \varepsilon \tilde{\sigma} \operatorname{co\tau \alpha }$.

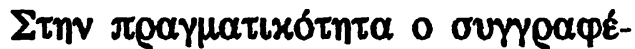

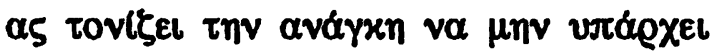

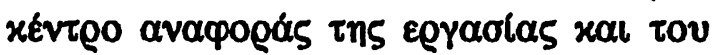

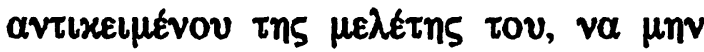
a

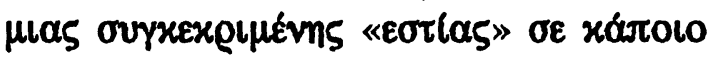
on $\mu$ elo tov xóopov.

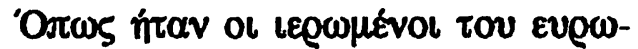

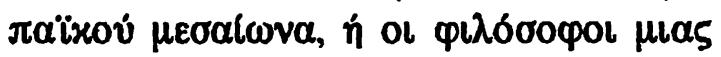

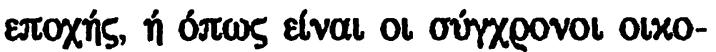

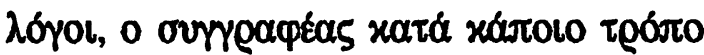

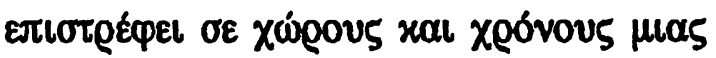

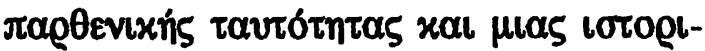

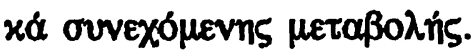

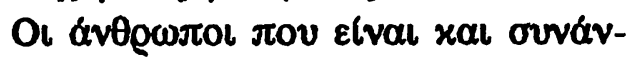

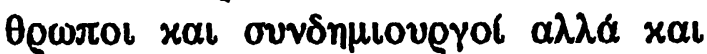

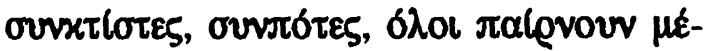

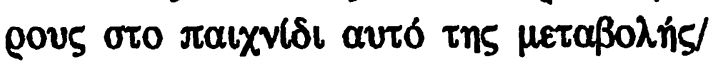

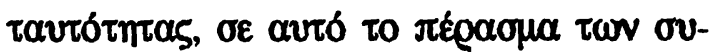
vópar xal tar oglar.

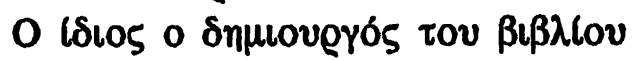

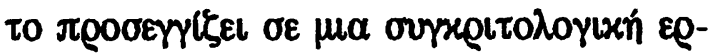

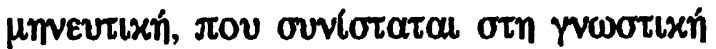

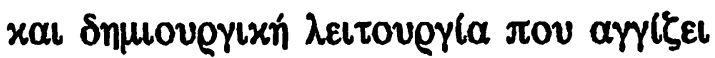

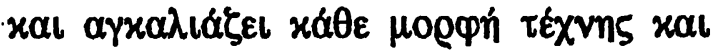

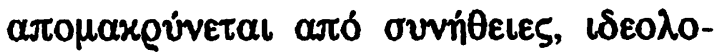

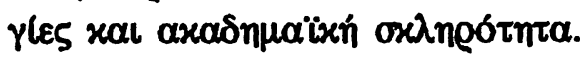

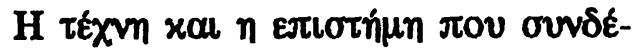

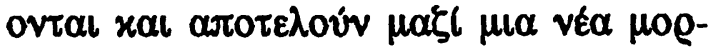

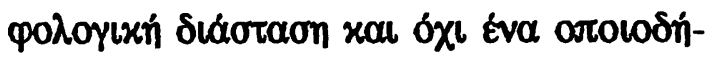

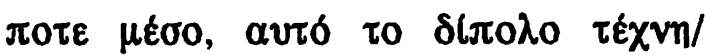

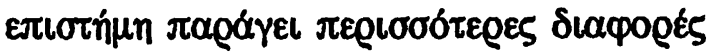


$\alpha \pi$ '

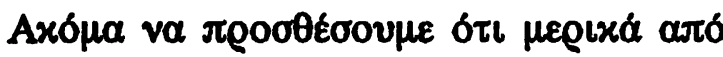

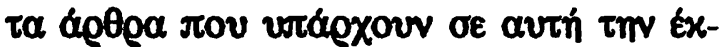

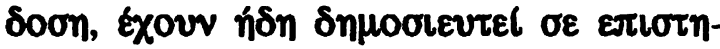

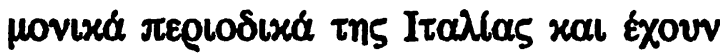

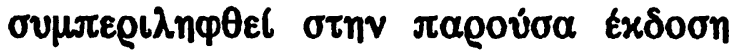

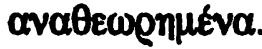

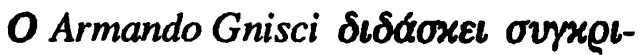

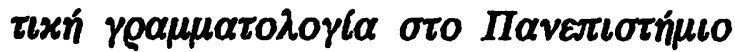

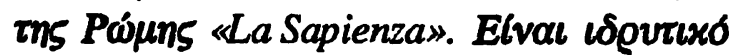

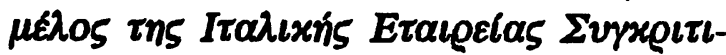

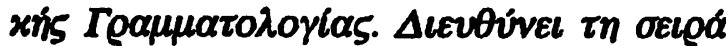

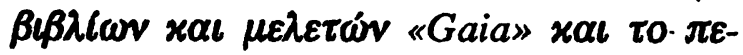

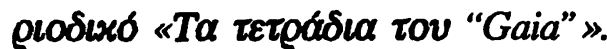

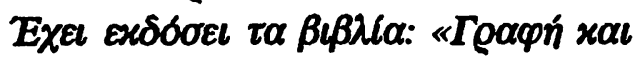

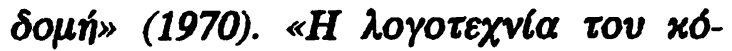

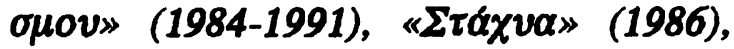

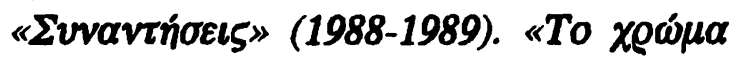

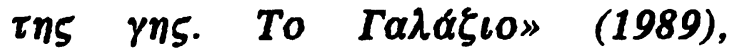

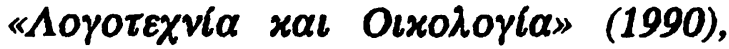

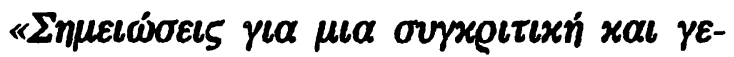

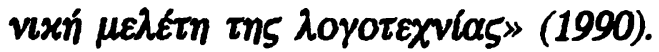

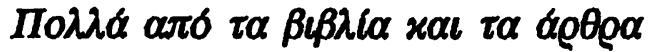

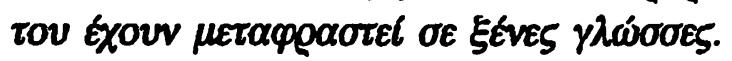

Búgar Iloodilons 